\title{
Functional Relationship of Thyroid Hormone-induced Lipogenesis, Lipolysis, and Thermogenesis in the Rat
}

\author{
Jack H. Oppenheimer, Harold L. Schwartz, James T. Lane, and Mary P. Thompson \\ Division of Endocrinology and Metabolism, Department of Medicine University of Minnesota, Minneapolis, Minnesota 55455
}

\begin{abstract}
Metabolic balance studies were carried out to determine the interrelationships of thyroid hormone-induced lipogenesis, lipolysis, and energy balance in the free-living rat. Intraperitoneal doses of $15 \mu \mathrm{g}$ triiodothyronine (T3)/100 $\mathrm{g}$ body wt per d caused an increase in caloric intake from $26.5 \pm 1.7$ (mean \pm SEM) $\mathrm{kcal} / 100 \mathrm{~g}$ per $\mathrm{d}$ to $38.1 \pm 1.5 \mathrm{kcal} / 100 \mathrm{~g}$ per $\mathrm{d}$. Food intake, however, rose only after 4-6 d of treatment and was maximal by the 8th day. In contrast, total body basal oxygen consumption rose by $24 \mathrm{~h}$ and reached a maximum by $4 \mathrm{~d}$. Since total urinary nitrogen excretion and hepatic phosphoenolpyruvate carboxykinase mRNA did not rise, gluconeogenesis from protein sources did not supply the needed substrate for the early increase in calorigenesis. Total body fat stores fell $\sim 50 \%$ by the 6th day of treatment and could account for the entire increase in caloric expenditure during the initial period of $\mathrm{T3}$ treatment. Total body lipogenesis increased within $1 \mathrm{~d}$ and reached a plateau 4-5 d after the start of T3 treatment. 15-19\% of the increased caloric intake was channeled through lipogenesis, assuming glucose to be the sole substrate for lipogenesis. The metabolic cost of the increased lipogenesis, however, accounted for only $3-4 \%$ of the T3-induced increase in calorigenesis. These results suggest that fatty acids derived from adipose tissue are the primary source of substrate for thyroid hormoneinduced calorigenesis and that the early increase in lipogenesis serves simply to maintain fat stores. Since the mRNAs coding for lipogenic enzymes rise many hours before oxygen consumption and lipolysis, these results suggest that $\mathrm{T3}$ acts at least in part by an early coordinate induction of the genes responsible for these processes. (J. Clin. Invest. 1991. 87:125-132.) Key words: lipogenesis $\bullet$ lypolysis • thermogenesis • triiodothyronine - phosphoenolpyruvate carboxykinase • gluconeogenesis
\end{abstract}

\section{Introduction}

Thyroid hormone both increases the formation of fatty acids and augments the lipolysis of triacyl glycerol. The effect of thyroid hormones on lipogenesis is due to increased expression of genes coding for lipogenic enzymes (1-3) and proteins closely related to lipogenesis, such as hepatic S14(4). The effect

Address correspondence and reprint requests to Dr. Jack H. Oppenheimer, Division of Endocrinology \& Metabolism, Department of Medicine, Box 91 UMHC, University of Minnesota, 515 Delaware Street SE, Minneapolis, MN 55455. Dr. Mary P. Thompson is on sabbatical leave from the Department of Biochemistry, University of Otago, P.O. Box 56, Dunedin, New Zealand.

Received for publication 30 May 1990 and in revised form $10 \mathrm{Au}$ gust 1990.

J. Clin. Invest.

(c) The American Society for Clinical Investigation, Inc.

$0021-9738 / 91 / 01 / 0125 / 08 \$ 2.00$

Volume 87, January 1991, 125-132 of thyroid hormone on $\mathrm{S} 14$ gene expression is apparent within 10-20 min after triiodothyronine (T3) administration $(5,6)$ and that on malic enzyme within 1-2 h (7). In contrast, a detectable increase in fatty acid synthesis does not occur until some 12-16 h later (8), presumably because of the comparatively long $t_{1}$ of accumulation of the enzyme proteins.

Equally well established are the effects of thyroid hormone in augmenting catecholamine stimulation of lipolysis (9-12) although the underlying molecular mechanisms are more poorly understood. Two hypotheses have been advanced. The first holds that thyroid hormone augments the activity of hormone-sensitive lipase by stimulating the expression of one or more genes coding for proteins involved in the transduction of the membrane signal $(13,14)$. The second contends that thyroid hormone reduces the level of the low $\mathrm{km}$ phosphodiesterase (15-17), thereby increasing intracellular levels of cyclic AMP.

The functional relationships of thyroid hormone-induced lipogenesis and lipolysis to the overall metabolic effects of thyroid hormones are poorly understood. We have recently estimated that the energy required for the thyroid hormone-stimulated increase in fatty acid synthesis accounts for less than $10 \%$ of the increase in resting oxygen consumption in the transition between the hypothyroid and hyperthyroid state. These calculations were made on the basis of measurements of the rate of lipogenesis as determined from the rate of tritium incorporation into total body fatty acids from injected ${ }^{3} \mathrm{H}_{2} \mathrm{O}$, the assumption of coupled oxidative phosphorylation, and published values of the rate of oxygen consumption in thyroid hormonetreated rats $(18,19)$.

A major problem in these studies was that measurements of oxygen consumption in the published studies were performed in restrained animals over comparatively short periods and thus might not adequately reflect oxygen consumption in the free living state. We therefore adopted an alternate approach for assessing thermogenesis, one based on the determination of caloric balance. In the course of these experiments, we made observations on the time course of the effect of thyroid hormone on body weight, food consumption, urinary nitrogen excretion, body lipid composition, and the rate of total body lipogenesis. These data allowed us not only to obtain an independent estimate of the contribution of total body fatty acid synthesis to total body energy expenditure, but also to infer the functional interrelationship of thyroid hormone-induced lipogenesis, lipolysis, and thermogenesis.

\section{Methods}

Male Sprague-Dawley rats weighing 175-200 g supplied by BioLab, Inc. (St. Paul, MN) were used in these studies. Rats were individually housed in metabolic cages with free access to food and water. Studies

1. Abbreviations used in this paper: BW, body weight; PEPCK, phosphenolpyruvate carboxykinase; T3, triiodothyronine. 
were carried out to assess the effect of thyroid hormone on the rate of growth and food consumption. For each study, experimental and control groups, each consisting of four animals, were studied simultaneously. Daily growth rate and food intake were assessed in all groups for a period of nine control days preceding the start of $\mathrm{T} 3 \mathrm{administra-}$ tion. Daily urine collections, starting $3 \mathrm{~d}$ before onset of hormone treatment, were assayed for total nitrogen by a chemiluminescent method (20) (Antec Instruments, Inc., Houston, TX). Experimental groups were injected with a single daily intraperitoneal dose of $5,10,15$, or 50 $\mu \mathrm{g} \mathrm{T} 3 / 100 \mathrm{~g}$ body weight (BW), whereas the control group was injected with the appropriate vehicle, $0.05 \mathrm{M} \mathrm{NaOH}$. Treatment was carried out for a total of $14 \mathrm{~d}$.

Caloric balance. Calories expended were estimated from the following formula:

Calories expended $/$ day $=$ (calories ingested - calories excreted

- calories retained as body weight)/day.

Calories ingested were determined from the weight of Purina Chow (diet \#5001; Ralston-Purina Co., St. Louis, MO) eaten and the fuel composition listed by the manufacturer. $100 \mathrm{~g}$ of chow contained 49.0 $\mathrm{g}$ carbohydrate, $4.5 \mathrm{~g}$ of fat, and $23.4 \mathrm{~g}$ of protein. The residual $23.1 \mathrm{~g}$ were in the form of undigestible fiber, salts, and vitamins. Caloric equivalents were assumed to be $9.3 \mathrm{kcal} / \mathrm{g}$ fat, $4.1 \mathrm{kcal} / \mathrm{g}$ carbohydrate, and $4.1 \mathrm{kcal} / \mathrm{g}$ protein. The digestible caloric content of $1 \mathrm{~g}$ of chow was, therefore, $3.39 \mathrm{kcal}$. Bomb calorimetry (model 1341; Parr Instrument Co., Moline, IL) revealed a gross caloric content of $4.28 \mathrm{kcal} / \mathrm{g}$ of chow. The difference between the total measured calories and the estimated digestible nutrient content presumably represents the undigestible fiber content. To verify this assumption and to detect whether or not hyperthyroidism caused any change in fecal excretion of calories, pooled 4-d fecal collections for each group as well as samples of chow were analyzed by bomb calorimetry. Studies were performed in groups of animals both before and after 2 wk of treatment with daily doses of 15 or $50 \mu \mathrm{g} \mathrm{T} 3 / 100 \mathrm{~g} \mathrm{BW}$ and in a third group before and after injection of vehicle alone. In the three groups before treatment, the average percentage of total ingested calories excreted in the feces was $21.5 \%$ and in the vehicle-treated group, $20.6 \%$. These values correspond closely to the $20.8 \%$ of gross caloric content of food estimated to be derived from undigestible fiber. In the two T3-treated groups the corresponding average was $25.8 \%$. Thus, hyperthyroidism appears to be associated with a small decrease in absorption of nutrients. This difference has been taken into account in calculating caloric intake in the hyperthyroid groups.

Food intake. Between 4-6 d after the start of T3 treatment food intake increased. When both the rate of growth and the rate of food consumption had stabilized, the average daily food consumption for a 6-d period was determined both in control and in experimental groups together with the average daily rate of weight gain during these periods. The increment in weight was assumed to have the same fuel composition as the remainder of the rat. In studies to be described under $\mathbf{R e}-$ sults, fat accounted for $12.1 \%$ of total body weight in euthyroid rats and 7.5 and $5.8 \%$ in rats treated with 15 and $50 \mu \mathrm{g} \mathrm{T} 3 / 100 \mathrm{~g} \mathrm{BW}$, respectively. $20 \%$ of the body weight was assumed to be in the form of protein and carbohydrate. Although this assumption is an approximation only, the effect of changes in body weight were relatively small in comparison to the quantity of ingested calories when determining caloric expenditure. Available data $(42,43)$ suggest the fat content of the accumulated body mass in young rats growing from 100 to $300 \mathrm{~g} \mathrm{BW}$ is $\sim 10 \%$, close to the values used in our calculations. These data indicate that fraction of total body mass represented by fat rises only slowly. In addition, Babineau and Page (44) reported that the water content of fat-free body mass is constant and independent of the size of fat depots. The approximations were therefore considered to be entirely justifiable. With the $50-\mu \mathrm{g}$ dose of $\mathrm{T} 3$ some animal groups lost rather than gained weight. In these cases the value for "retained calories" in the defining equation presented above thus assumes a negative value.

Lipogenesis and lipid content. The rate of lipogenesis in whole ani- mals was determined by the method of Stansbie et al. (21) as previously applied in our laboratory (8). $3 \mathrm{mCi}$ of tritiated water were injected per rat intraperitoneally at $0800 \mathrm{~h}$. Animals were killed after $30 \mathrm{~min}$ by exsanguination from the aorta under light ether anesthesia and a uniform homogenate of the total carcass prepared. Circadian variation in total body lipogenesis was determined at 4-h intervals over a 24-h period. Maximum levels were obtained between 0400 and $0800 \mathrm{~h}$, whereas a lower but constant level was observed between noon and midnight. The value obtained at $0800 \mathrm{~h}$ was $125.8 \%$ of the average of the six values measured throughout the day. Therefore, in subsequent studies in which a measurement was made only at $0800 \mathrm{~h}$, the value was multiplied by a factor of 0.778 to obtain an average hourly value for lipogenesis. Total body lipids were extracted by the method of Bligh and Dyer (22).

Oxygen consumption. To determine the time course of oxygen consumption after the initiation of triiodothyronine treatment, sequential determinations of oxygen consumption were made in animals over a $7-d$ period. Unanesthetized animals were placed in sealed plexiglass chambers $(10 \times 17 \times 30 \mathrm{~cm})$ and allowed to acclimate for $15 \mathrm{~min}$ before testing. Oxygen consumed was determined from air samples withdrawn from the chamber through sealable ports at the start and end of a 15-min test period. Measurements were made with a Radiometer blood gas analyzer (model ABL 300; Copenhagen) through the courtesy of Mr. Michael Boyle, Associate Director, Cardio-Respiratory Services, University of Minnesota.

Quantitation of $m R N A$ levels. Determination of the levels of mRNA for adipose tissue hormone-sensitive lipase and hepatic phosphoenolpyruvate carboxykinase (PEPCK) was carried out by quantitation of dot blots (23) using videodensitometry as previously described (24). The cDNA probe for hormone-sensitive lipase was kindly provided by Dr. M. C. Schotz, Wadsworth VA Medical Center (Los Angeles, CA) and that for PEPCK by Dr. Richard Hanson, Case Western Reserve University (Cleveland, $\mathrm{OH}$ ).

\section{Results}

Figs. 1 and 2 illustrate the effects of 15 or $50 \mu \mathrm{g} \mathrm{T} 3 / 100 \mathrm{~g} \mathrm{BW}$ on the growth rate and food consumption of Sprague-Dawley rats in one of a series of five studies (Experiment 2, Table I). Those animals treated with the $15-\mu \mathrm{g}$ dose uniformally continued to gain weight although at a diminished rate, $1.4 \pm 0.4 \%$ (mean \pm SEM) of initial $\mathrm{BW} / \mathrm{d}$ as compared with that of control animals, $2.2 \pm 0.4 \%$. Animals injected with the higher dose showed no increase in body weight during the period of treatment.

Food consumption in the control group decreased slightly with time indicating, as previously reported (25), that food consumption per $100 \mathrm{~g} \mathrm{BW}$ decreases with age. In the animals treated with $15 \mu \mathrm{g} \mathrm{T} 3 / 100 \mathrm{~g} \mathrm{BW}$ a sudden increase in food intake occurs $5 \mathrm{~d}$ after the start of injections and rises from $8.1 \pm 0.3 \mathrm{~g} / 100 \mathrm{~g} \mathrm{BW}$ to $11.5 \pm 0.2 \mathrm{~g} / 100 \mathrm{~g} \mathrm{BW}$. A similar lag time in the rise of food consumption is observed in the animals treated with $50 \mu \mathrm{g} \mathrm{T} 3 / 100 \mathrm{~g} \mathrm{BW}$. Food consumption in this higher dose group was somewhat greater, $12.2 \pm 0.2 \mathrm{~g} / 100 \mathrm{~g}$ BW. Similar results were observed in each of the groups studied with this protocol. The average daily food intake for all five experiments rose from $7.8 \pm 0.3 \mathrm{~g} / 100 \mathrm{~g} \mathrm{BW}$ in the control groups to $11.5 \pm 0.4 \mathrm{~g} / 100 \mathrm{~g} \mathrm{BW}$ and $11.9 \pm 0.3 \mathrm{~g} / 100 \mathrm{~g} \mathrm{BW}$ in the $15-$ and $50-\mu \mathrm{g} T 3$ dose groups, respectively.

Rates of caloric consumption and expenditure observed in each of the five experiments performed are listed in Table I. Included in this table are the measurements of lipogenesis performed 2 wk after the start of T3 administration. In the five studies performed with a dose of $15 \mu \mathrm{g} \mathrm{T} 3 / 100 \mathrm{~g} \mathrm{BW}$, there was an average $44 \%$ increase in the rate of caloric expenditure, from 

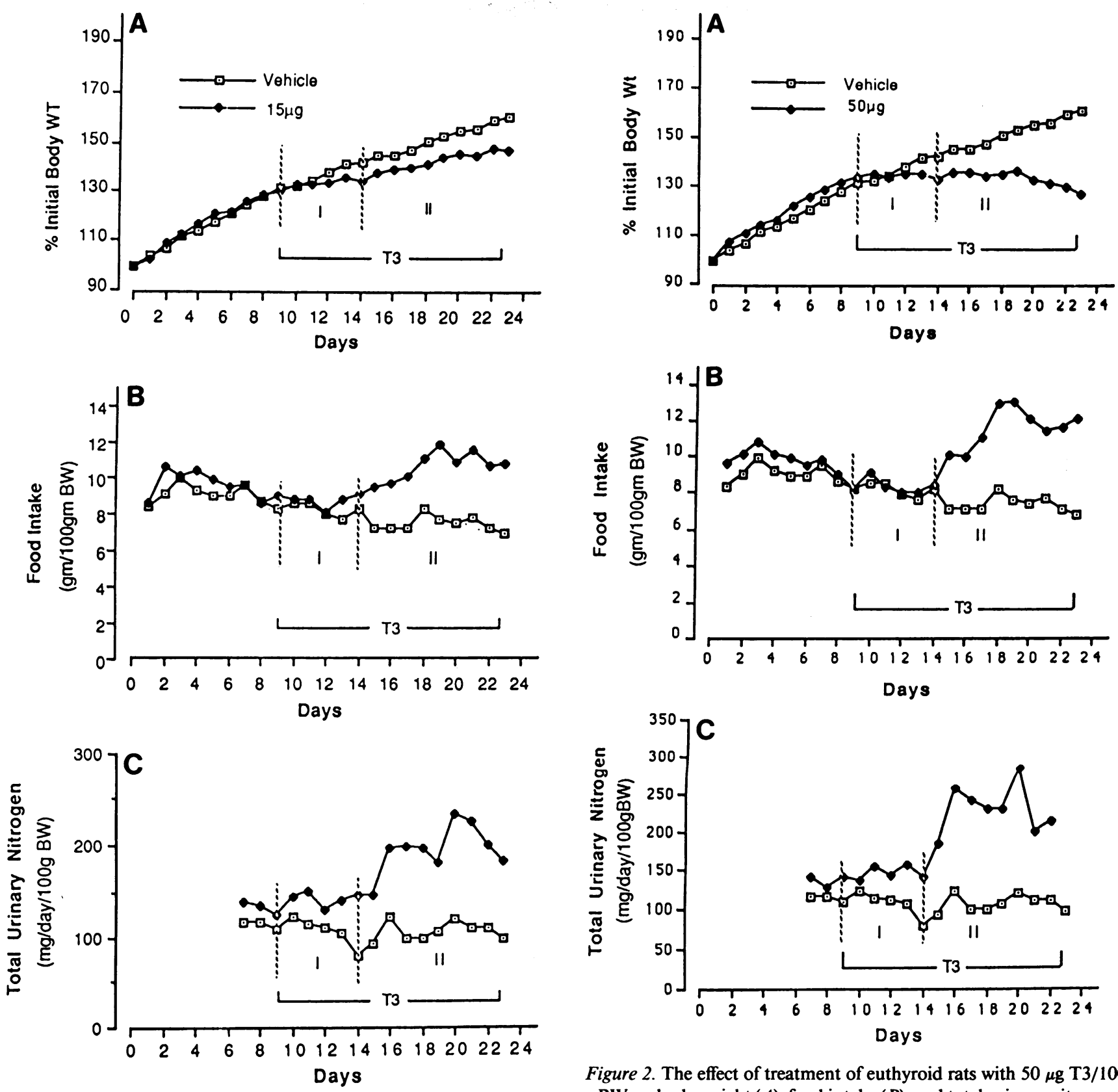

Figure 1. The effect of treatment of euthyroid rats with $15 \mu \mathrm{g} \mathrm{T} 3 / 100$ $\mathrm{g}$ BW on body weight $(A)$, food intake $(B)$, and total urinary nitrogen (C). After a 9-d control period rats were treated with the indicated dose of T3 for $14 \mathrm{~d}$. Body weight and food intake were measured daily throughout the study. Daily total urinary nitrogen measurements were begun $3 \mathrm{~d}$ before hormone treatment and continued to the end of the study. The lower average of total urinary nitrogen values in the control group resulted from the consistently lower values observed in one animal in the group. Data are derived from Experiment 2 listed in Table I. Initial body weights were $194 \pm 3$ $\mathrm{g}($ mean $\pm \mathrm{SEM} ; n=4)$ in the control group and $187 \pm 9 \mathrm{~g}(n=5)$ for the treated rats. The hatched vertical lines designate the initial period of $\mathrm{T} 3$ treatment during which food intake is unaffected.

$26.5 \pm 1.7 \mathrm{kcal} / 100 \mathrm{~g} \mathrm{BW} / \mathrm{d}$ in the euthyroid control to $38.1 \pm 1.5 \mathrm{kcal} / 100 \mathrm{~g} \mathrm{BW}$ per $\mathrm{d}$ in the hyperthyroid state. This increase is likely not quite maximal since in each study in which the 50- $\mu$ g dose was used (Table I, Experiments 2, 3, and

Figure 2. The effect of treatment of euthyroid rats with $50 \mu \mathrm{g} \mathrm{T} 3 / 100$ g BW on body weight $(A)$, food intake $(B)$, and total urinary nitrogen (C). Data are taken from Experiment 2, Table I. See legend to Fig. 1 for experimental details. Initial body weights for the T3-treated group were $193 \pm 5 \mathrm{~g}(n=5)$. The control group is the same as that represented in Fig. 1.

4) a small further increase was observed. The reduction in the rate of weight gain in the T3-treated animals reflects a diversion of ingested calories to energy expenditure. On the basis of the estimated caloric equivalent of the observed weight gain (see Methods), our findings suggest that in control animals $87 \%$ of the ingested calories are expended whereas the remaining $13 \%$ are reflected in the weight gain. In the animals treated with 15 $\mu \mathrm{g} \mathrm{T} 3 / 100 \mathrm{~g} \mathrm{BW}, 95 \%$ of the calories ingested are expended and only $5 \%$ stored. The higher dose of $50 \mu \mathrm{g} \mathrm{T} 3 / 100 \mathrm{~g} \mathrm{BW}$ induced a rate of energy expenditure that actually exceeded the caloric intake in two of the three experiments and was reflected in a loss of body weight. 
Table I. Effect of Thyroid Hormone on Caloric Intake and Expenditure

\begin{tabular}{|c|c|c|c|c|c|c|}
\hline Experiment & Dose & $\begin{array}{l}\text { Calories* } \\
\text { ingested }\end{array}$ & $\begin{array}{l}\text { Caloriest } \\
\text { retained }\end{array}$ & $\begin{array}{c}\text { Calories } \\
\text { expended }\end{array}$ & Lipogenesis & $\frac{\Delta \text { Lipogenesis } \times 100^{\prime \prime}}{\Delta \text { Caloric flux }}$ \\
\hline \multirow[t]{2}{*}{1} & 0 & 32.5 & 4.7 & 27.8 & & \\
\hline & $15 \mu g$ & 40.6 & 4.5 & 36.1 & & ND \\
\hline \multirow[t]{3}{*}{2} & 0 & 27.5 & 3.6 & 23.9 & 21.2 & \\
\hline & $15 \mu \mathrm{g}$ & 36.3 & 2.2 & 34.1 & 40.1 & 17.2 \\
\hline & $50 \mu \mathrm{g}$ & 38.5 & 0.5 & 38.0 & 66.9 & 32.0 \\
\hline \multirow[t]{3}{*}{3} & 0 & 23.1 & 1.6 & 21.5 & 25.6 & \\
\hline & $15 \mu \mathrm{g}$ & 33.8 & 0.7 & 33.1 & 43.0 & 13.1 \\
\hline & $50 \mu \mathrm{g}$ & 38.3 & $(-1.5)$ & 40.3 & 49.9 & 12.4 \\
\hline \multirow[t]{3}{*}{4} & 0 & 23.9 & 1.5 & 22.4 & & \\
\hline & $15 \mu \mathrm{g}$ & 33.8 & 0.2 & 33.6 & & ND \\
\hline & $50 \mu \mathrm{g}$ & 35.6 & $(-1.9)$ & 37.5 & & ND \\
\hline \multirow[t]{4}{*}{5} & 0 & 25.4 & 3.8 & 21.6 & 23.5 & \\
\hline & $5 \mu \mathrm{g}$ & 29.3 & 1.9 & 27.4 & 33.5 & 20.5 \\
\hline & $10 \mu \mathrm{g}$ & 31.0 & 0.4 & 30.6 & 37.3 & 19.8 \\
\hline & $15 \mu \mathrm{g}$ & 32.7 & 0.7 & 32.0 & 48.7 & 27.2 \\
\hline
\end{tabular}

Effect of T3 on total energy consumption and expenditure. Groups of 4 or 5 rats were treated with T3 as described in Methods. Data are derived from the measured food intake during the last 6 days of treatment when an apparent new steady state value had been achieved. One gram of Purina Chow contains $3.39 \mathrm{kcal} / \mathrm{gm}$. Calories retained represent the caloric value of the average daily weight gain or loss during this 6 day period and were calculated as described in Methods. Measurement of lipogenesis was done on the last day of the indicated studies by the method of Stansbie et al (21). The contribution of the increment in lipogenesis to the change in total energy expenditure was calculated from the caloric content of the glucose required for hormone-induced fatty acid synthesis as a fraction of the increase in caloric intake. ${ }^{*}$ Values represent mean kcal/100 g BW per $\mathrm{d}$ for groups of four or five animals. ${ }^{\ddagger}$ Caloric value of body weight gained or lost during treatment. 8 Expressed as $\mu \mathrm{mol}$ palmitate synthesized/h per $100 \mathrm{~g} \mathrm{BW}$. "Percentage of the increased caloric intake expressed as glucose equivalents channeled through lipogenesis.

In Experiments 2, 3, and 4 (Table I), we have measured total body lipogenesis expressed as $\mu$ mol of palmitate equivalents synthesized. Since standard equations show that $4.5 \mathrm{~mol}$ of glucose are required to synthesize $1 \mathrm{~mol}$ of palmitate, we can calculate the mass of glucose equivalents required to synthesize the moles of palmitate produced in response to thyroid hormone administration. Assuming glucose to be the sole source of substrate, the increment in lipogenesis produced by a daily dose of $15 \mu \mathrm{g} \mathrm{T} 3 / 100 \mathrm{~g} \mathrm{BW}$ required an average of $19.2 \%$ of the calories ingested. For a dose of $50 \mu \mathrm{g} \mathrm{T} 3 / 100 \mathrm{~g} \mathrm{BW}$, an average of $22.2 \%$ of the ingested calories were channeled into the synthesis of fatty acids.

Although these calculations provide a gross estimate of the percentage of glucose channeled to fatty acid synthesis, they do not represent the caloric cost of synthesis. This is the case since the fatty acids produced are ultimately oxidized to yield the greatest share of the potential caloric content of the glucose used for their synthesis. Flatt (26) has estimated that only 27 mol of ATP of the potential $162 \mathrm{~mol}(4.5 \times 36 \mathrm{~mol}$ of ATP $/ \mathrm{mol}$ glucose) are used in the process of lipogenesis, a loss of $16.7 \%$. Thus, the metabolic cost of the T3-induced increase in lipogenesis in the group treated with $15 \mu \mathrm{g} \mathrm{T} 3 / 100 \mathrm{~g} \mathrm{BW}$ is only $3.2 \%$ $(0.167 \times 19.2 \%)$ of the increased caloric flux. In the group treated with $50 \mu \mathrm{g} \mathrm{T} 3 / 100 \mathrm{~g} \mathrm{BW}$ this amounts to $3.7 \%(0.167$ $\times 22.2 \%$ ).

Previous studies $(18,19)$ had shown that oxygen consumption increases within $1 \mathrm{~d}$ after the start of $\mathrm{T} 3$ treatment and reaches maximal values only 4-5 d after the start of hormone treatment. Given the observation that food intake does not increase until 4-6 d after the start of T3 therapy, we were interested in defining the source of fuel which sustains the increased metabolic demand during this period. To ascertain whether or not gluconeogenesis from protein sources might provide this fuel, urinary collections were performed as illustrated in Figs. 1 $C$ and $2 C$. The results clearly show that during the first $5 \mathrm{~d}$ of T3 administration there was no detectable increase in urinary nitrogen excretion. An augmented urinary nitrogen excretion became evident only after the increase in food intake on day 5 . In addition, the level of the hepatic mRNA coding for PEPCK did not change in response to $7 \mathrm{~d}$ of treatment with $50 \mu \mathrm{g}$ T3/100 g BW (euthyroid: $135 \pm 14$ OD/ $\mu$ g RNA; hyperthyroid: $110 \pm 24 \mathrm{OD} / \mu \mathrm{g}$ RNA, $n=4$ /group). This enzyme is generally regarded to be the rate-limiting enzyme in gluconeogenesis and is regulated by alterations in protein mass resulting from changes in mRNA levels (27). Thus gluconeogenesis from a protein source is unlikely to fuel the early $\mathrm{T} 3$-induced increase in oxygen consumption. Since the known carbohydrate reserves in animals are relatively small (28), it appeared highly unlikely that glycogen could serve as the sole source of the needed fuel.

By exclusion of other fuels therefore, fat seemed to be the most likely source of the calories and experiments were performed to test this hypothesis. The results of serial measurements of total body fat are illustrated in Fig. 3. Results are expressed as the grams of fat extracted per $100 \mathrm{~g} \mathrm{BW}$. The initial value for total body fat content in euthyroid rats was $12.1 \mathrm{~g} / 100 \mathrm{~g} \mathrm{BW}$. In rats treated with $50 \mu \mathrm{g} \mathrm{T} / 100 \mathrm{~g} \mathrm{BW}$ no changes in total body fat content were apparent $1 \mathrm{~d}$ after the start of injections. A decrease of $25 \%$ occurred between 1 and 3 $\mathrm{d}$ and body fat content continued to decrease so that by $6 \mathrm{~d}$ approximately half of the initial body fat content remained. The percentage of body fat did not undergo any further change 


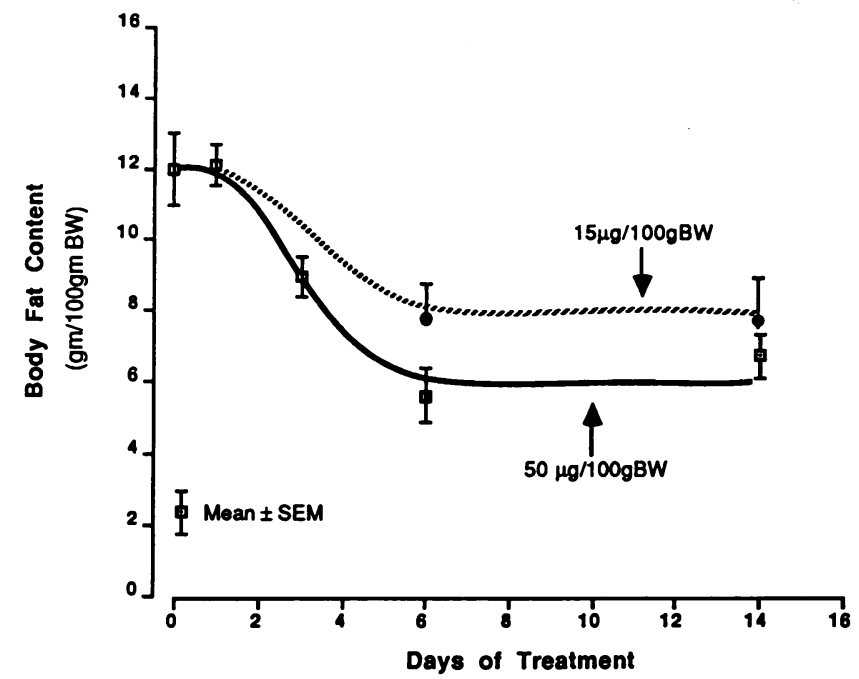

Figure 3. Effect of $\mathrm{T} 3$ treatment on total body lipid content. Rats were treated with the indicated daily doses of $\mathrm{T} 3$ for $1-14 \mathrm{~d}$. Total lipids were extracted by the method of Bligh and Dyer (22) from homogenates of the total carcass. Each point represents the mean \pm SEM for groups of four rats.

for the remainder of the 2-wk period of the study. Animals receiving the $15-\mu \mathrm{g}$ dose lost a smaller percentage of their initial fat stores so that after 6 and $14 \mathrm{~d}$ of treatment they contained $7.5 \mathrm{~g}$ fat $/ 100 \mathrm{~g} \mathrm{BW}$.

To provide a quantitative estimate of caloric expenditure during the first $5 \mathrm{~d}$ of the experiment we performed serial measurements of oxygen consumption (Fig. 4). The results were similar to previously published results $(18,19)$ both with regard to the actual levels of oxygen consumption attained and, more importantly from the perspective of our studies, the time course of response. The area under the curve of increasing oxygen consumption during the first $5 \mathrm{~d}$ divided by the maximum observed value under steady-state conditions was 0.76 . Thus, $76 \%$ of the maximal rate of oxygen consumption, as inferred from the steady-state caloric balance studies, could be assumed to represent the average rate of caloric expenditure during the first $5 \mathrm{~d}$. The caloric value of lost body fat could be calculated from the data presented in Fig. 4. For both 15- and 50- $\mu$ g doses, there was close correspondence between the estimated T3-induced caloric expenditure during the first $5 \mathrm{~d}$ and the calories lost through the depletion of lipid stores (Table II). Given the experimental errors of our methods the fuel source for the expended energy appears to be derived entirely from fat.

\section{Discussion}

Our findings show that caloric balance studies provide a reliable and reproducible technique for determining energy expenditure under steady-state conditions. The validity of the technique is dependent on two important assumptions, $(a)$ that virtually $100 \%$ of digestible food is absorbed; and $(b)$ that the caloric equivalence of the changes in weight gain can be adequately estimated. Bomb calorimetry of samples of chow and fecal excreta supported the first assumption both in the basal and thyroid hormone-treated states. Although the second assumption has not been directly tested, the contribution of weight changes to total caloric intake is relatively small, thus

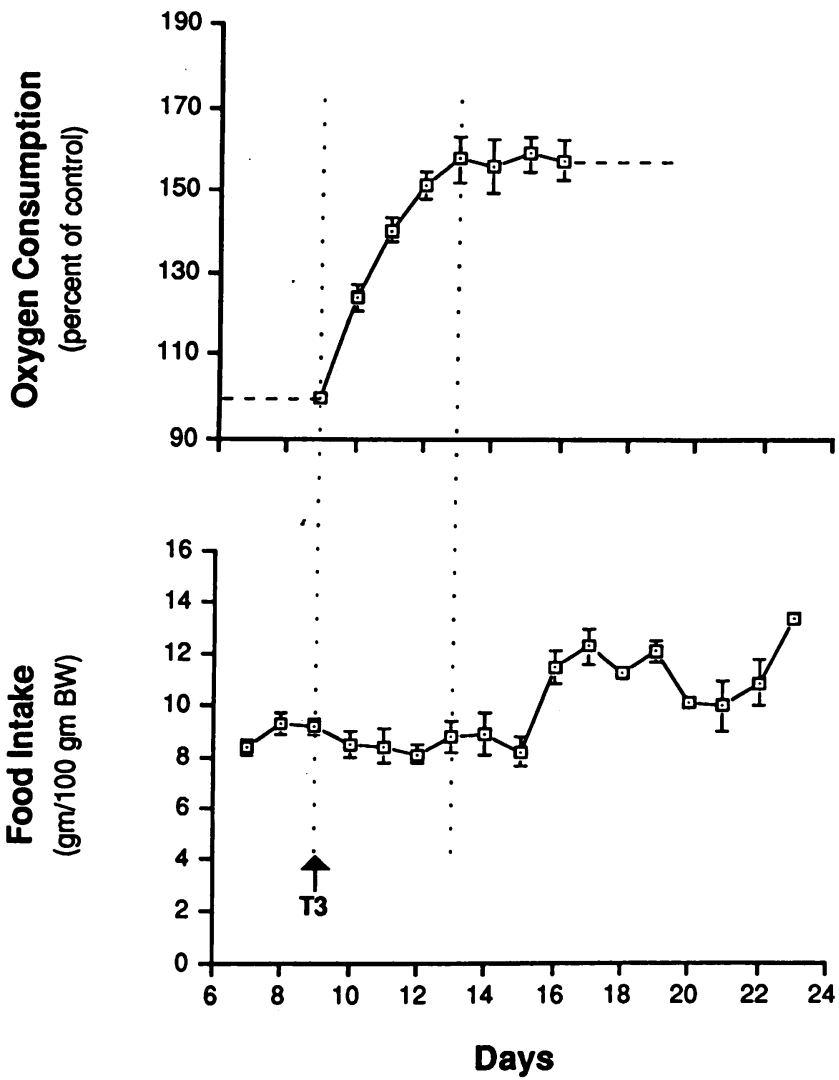

Figure 4. Sequential changes in basal oxygen consumption in euthyroid rats treated with $50 \mu \mathrm{g} \mathrm{T} 3 / 100 \mathrm{~g} \mathrm{BW}$. Animals were administered the daily dose of hormone at $0900 \mathrm{~h}$ after measurement of oxygen consumption. Each point represents the mean \pm SEM for a single group of six rats that were serially studied for $7 \mathrm{~d}$. Basal value of oxygen consumption in the untreated group was $92.5 \pm 1.4 \mathrm{ml}$ $0_{2} / 100 \mathrm{~g}$ per $\mathrm{h}$. The lower panel represents the effect of the same dose of $\mathrm{T} 3$ on food intake in a separate group of five rats (mean $\pm \mathrm{SEM}$; Experiment 4, Table I) and is included to emphasize the much more rapid response of calorigenesis to hormone administration.

minimizing potential errors from estimating the composition of the newly accumulated (or lost) tissue. The caloric balance technique enjoys a distinct advantage over conventional measurements of oxygen consumption insofar as the approach may provide a more reliable guide to calorigenesis in the free living animal. From the caloric value of the ingested food in euthyroid rats, $26.4 \mathrm{kcal} / 100 \mathrm{~g} \mathrm{BW} / \mathrm{d}$, we may calculate a rate of oxygen consumption of $228 \mathrm{ml} \mathrm{O} / 100 \mathrm{~g}$ per $\mathrm{h}$. This value agrees well with the value of $214 \mathrm{ml} \mathrm{O} / 100 \mathrm{~g}$ per $\mathrm{h}$ measured in a free living Sprague-Dawley rat in a thermal chamber (Dr. Elliot Danforth, University of Vermont, personal communication), and is at least twice the value obtained under resting conditions by us in this study $(92 \mathrm{ml} / 100 \mathrm{~g}$ per $\mathrm{h})$ as well as by previous authors $(18,19)$. The increased oxygen consumption in the free living animal is presumably in large measure due to increased muscular work performed. We have used the caloric balance technique to assess the contribution of total body lipogenesis to thyroid hormone-stimulated thermogenesis. The estimate provided in these studies suggests that the caloric cost of lipogenesis accounts for only $3-4 \%$ of the increase in energy utilization due to thyroid hormone administration, a half to a third the estimate previously reported (8). Our earlier studies 
Table II. Caloric Value of Lost Body Fat

\begin{tabular}{lrr}
\hline & \multicolumn{2}{c}{ Treatment dose } \\
\hline & $15 \mu g$ & $50 \mu g$ \\
$\Delta$ Calories expended $/ 100 \mathrm{~g}^{*}$ & 44.1 & 53.2 \\
Grams of fat lost/100 $\mathrm{g}$ & 4.5 & 6.2 \\
Caloric content of fat & 41.9 & 57.7 \\
\hline
\end{tabular}

Caloric value of total body fat lost during T3 treatment. From the data in Table I we calculated the caloric value of the increment in food intake for each T3-treated group and, as described in Results, multiplied by a factor of 0.76 . The product represents the change in caloric expenditure during the initial period of treatment before any change in food intake. The caloric content of the grams of total body fat lost during this same period can be calculated from the data in Fig. 4. * Difference between treated and control group during the initial $6 \mathrm{~d}$ of treatment.

yielded values of 5 or $10 \%$ of the total oxygen consumption, depending on which of the two published values of oxygen consumption were used for the calculation. Those latter values, however, were obtained in resting animals, and as indicated above, are one-half to one-third the levels of energy expenditure we have observed in the free living rat.

These studies of the time course of response of food consumption and body weight gain to $\mathrm{T} 3$ administration made us aware of a 4-6-d lag period between the start of T3 injections and the increase in food intake. Since published studies of oxygen consumption, as well as our own, suggested that the first $5 \mathrm{~d}$ after T3 administration were associated with a marked increase in oxygen consumption, we reasoned that some endogenous source of fuel was essential to meet the increased energy requirements during this period. Measurement of urinary nitrogen excretion as well as the lack of effect of T3 treatment on PEPCK mRNA effectively excluded the possibility that the fuel was supplied as a result of gluconeogenesis from protein sources. In contrast, the reduction in mass of total body fat fully accounted for the fuel required during the transition period between the start of $\mathrm{T} 3$ injections and the increased food intake observed 4-6 d later.

The mechanism underlying the reduction in total fat pool is of considerable interest. Although no direct enzymatic measurements were made, we believe that the reduction in total body fat is due to an enhanced activity of hormone sensitive lipase, the enzyme responsible for triacylglycerol hydrolysis in adipose tissue. Studies in our laboratory have also shown the level of the mRNA coding for this enzyme does not change with alterations in thyroid state (data not shown). This is consistent with the many studies demonstrating regulation of the activity of this enzyme through a cAMP-dependent phosphorylation-dephosphorylation mechanism (29). However, many investigators have shown that thyroid hormone administration increases the sensitivity of the lipolytic response to catecholamines (9-12). There is, nevertheless, no evidence suggesting that catecholamines are directly responsible for the thyroid hormone-induced lipolytic activity; the concentrations of catecholamines actually appear to be inversely related to the thyroidal state of the animal (30-32).

The molecular nature of the sensitization process also has received considerable attention (for review see reference 9).
Malbon and his colleagues have suggested that alteration in the transduction of the catechol receptor signal is responsible for the sensitization $(13,14)$. Most recently, these investigators have postulated that thyroid hormone acts to inhibit the expression of the mRNA for the $\beta$-subunit of G-proteins (14). Other investigators have proposed that thyroid hormone sensitization is related to changes in the activity of phosphodiesterase (15-17). Conflicting data exist with respect to the effect of thyroid hormone on the level of the beta adrenergic receptor in fat (9).

Regardless of these considerations, our data indicate that the hyperthyroid state is characterized by increased ingestion of fatty acids, an increased rate of fatty acid synthesis, an increased fractional turnover rate, as well as diminished total body pools of fatty acids. The total palmitate equivalent ingested in the euthyroid state averaged $1.37 \mathrm{mmol} / 100 \mathrm{~g}$ per d, and administration of 15 and $50 \mu \mathrm{g} \mathrm{T} 3 / 100 \mathrm{~g}$ per $\mathrm{d}$ increases the intake to 1.97 and $2.09 \mathrm{mmol} / 100 \mathrm{~g}$ per d, respectively. Rates of de novo synthesis of fatty acids in these groups are shown in Table I. The total turnover of palmitate equivalents in euthyroid animals and in animals treated with 15 and $50 \mu \mathrm{g}$ $\mathrm{T} 3 / 100 \mathrm{~g}$ per $\mathrm{d}$ is $1.93,3.02$, and $3.49 \mathrm{mmol} / 100 \mathrm{~g}$ per d, respectively. Preliminary chromatographic studies indicate that both in the euthyroid as well as in the T3-treated animals 20\% of the total lipid extracted is in the form of cholesterol and phospholipid. We can then estimate that the palmitate equivalent pool in euthyroid, $15-\mu \mathrm{g}$ and $50-\mu \mathrm{g}$ treated animals is 35.4 , 22.3 , and $17.2 \mathrm{nM} / 100 \mathrm{~g} \mathrm{BW}$. From the ratio of the total turnover to the pool size, the fractional turnover of palmitate equivalents can be calculated to be $0.055,0.135$, and $0.203 / \mathrm{d}$. These values correspond to a $t_{1}$ of body fat of $12.6,5.1$, and $3.4 \mathrm{~d}$, respectively. The augmented fractional turnover of the lipid pool therefore is entirely consonant with a concept that there is a tonic increase in lipolysis in the hyperthyroid state. These kinetic observations have broadened our view of the physiological significance of the concomitant increases in lipogenesis and lipolysis which accompany the hyperthyroid state. Our data suggest that fatty acids are initially derived from the increased lipolysis of adipose tissue triglyceride rather than from the de novo synthesis of fatty acids. The pool of free fatty acids in the body is exceedingly small in comparison with the total lipid pool. Furthermore, the fractional turnover rate of free fatty acids is high when compared with that of total body fatty acids. As a consequence, newly synthesized fatty acids are rapidly incorporated into the large pool of adipose tissue triacylglyceride and are not returned to the circulation until much later. These kinetic considerations simply emphasize the well known storage function of adipose tissue. Functionally, this is important since one can presume that an even rate of supply of fatty acids is needed to satisfy the requirement of the T3-stimulated peripheral metabolism. Given the intermittent nature of food intake, direct supply of de novo synthesized fatty acids would be a most inefficient process.

The increase in lipogenesis and lipolysis after thyroid hormone administration assures maintenance of adipose pools at operationally satisfactory levels. Since the rate of lipogenesis is increased by a factor of 2 , and fractional rate of turnover of total body pools by a factor of 3 to 4 , new steady-state levels of the lipid pool are one-third to one-half of those that exist in the euthyroid state. Ultimately, the energy requirements of the hyperthyroid state must be maintained by increased food consumption and, to a variable extent, diminished body growth. 
The rise in food intake, which follows some 4-6 d after the initiation of thyroid hormone treatment, may well occur as a result of a signal emitted from a contracted lipid pool as has previously been suggested $(33,34)$.

A primary increase in lipolysis is also essential in meeting demands imposed by any stimulus resulting in a sudden increase in need for metabolic fuel. A doubling in the rate of delivery of fatty acid on the basis of augmented lipogenesis alone with a constant fractional turnover of body lipids would require $12.6 \mathrm{~d}$, our estimated $t_{1 / 2}$ of lipid disappearance in the euthyroid state. Clearly this would be incompatible with the biochemical constraints of the system under study. Although a sudden change in thyroidal status is not a physiological stimulus, other stimuli leading to augmented metabolic expenditure clearly also require a rapid increase in the lipolytic rate.

The contribution of the various energy-requiring reactions which are stimulated by thyroid hormone to the increase in energy expenditure still require definition. Our studies suggest that fatty acid synthesis accounts for only $3-4 \%$ of the induced oxygen consumption. Additional ATP generation is also required for triacylglyceride formation, storage, and export (26). Maintenance of the sodium-potassium gradient from the cellular to the extracellular compartment has also been emphasized (35) though the percentage contribution to total thermogenesis remains controversial (36). It appears likely that the major energy sink for thyroid hormone-induced thermogenesis is the increased work of the heart through stimulation of myosin ATPase $(36,37)$ and perhaps sarcoplasmic reticulum $\mathrm{Ca}^{++}$ ATPase (38).

As indicated above, the molecular mechanism by which thyroid hormone increases lipolysis remains unclear. Failure to demonstrate expected changes in catecholamines in the hyperthyroid state does not necessarily exclude the possibility of some other unidentified hormonal agent acting to mediate the effects of thyroid hormone. However, a recent report from the laboratory of Torresani has suggested that thyroid hormone increases lipogenesis and lipolysis in a coordinate fashion in a predipocyte culture system (39). These experiments, therefore, do not appear to support the role of an unidentified hormonal mediator and strengthen the view espoused by Malbon that the thyroid hormone exerts its effects on lipolysis in the intact animal by stimulating the synthesis of a rate limiting protein involved in the transduction of the catecholamine signal.

The results of the studies summarized in our communication suggest that thyroid hormone independently and in a parallel fashion stimulates the expression of those genes involved in energy utilization, lipolysis, and lipogenesis. Thyroid hormone regulates the expression of genes coding for proteins involved in myocardial contractility and lipogenesis long before an increase in thermogenesis, lipolysis, and lipogenesis can be demonstrated. Hormonal induction of lipogenesis therefore is not determined exclusively by feedback signals from depleted fat depots. By analogy, it appears possible that thyroid hormoneinduced lipolysis is not solely determined by thyroid hormonestimulated energy utilization.

Although our studies have been confined to an analysis of the transition from the euthyroid to the hyperthyroid state, we speculate that a similar metabolic transition also characterizes the transition from the hypo- to the euthyroid state. Even though the thyroid hormone receptors have been identified in the very earliest vertebrates (40), thyroid hormones have had no demonstrable effect on lipogenesis and oxygen consump- tion in these forms $(40,41)$. Not until the evolution of the homeotherm some 200 million years ago did thyroid hormone assume its role in inducing thermogenesis. It appears probable that this was achieved by evolutionary pressures which allowed the T3 receptor complex to regulate the expression of genes involved in energy utilization, lipolysis, and lipogenesis.

\section{Acknowledgments}

The authors appreciate the excellent technical assistance of Mr. P. J. Pederson and the editorial help of Ms. Betty Romani and Mr. Jeff Smyser.

Supported by National Institutes of Health Grants DK-190812 (to Dr. Oppenheimer) and NRSA 0800-8668 (to Dr. Lane).

\section{References}

1. Goodridge, A. G. 1978. Regulation of malic enzyme synthesis by thyroid hormone and glucagon: inhibitor and kinetic experiments. Mol. Cell. Endocrinol. 11:19-29.

2. Towle, H. C., C. N. Mariash, and J. H. Oppenheimer. 1980. Changes in the hepatic levels of messenger ribonucleic acid for malic enzyme during induction by thyroid hormone or diet. Biochem. 19:579-585.

3. Miksicek, R. V., and H. C. Towle. 1982. Changes in the rates of synthesis and messenger RNA levels of hepatic glucose-6-phosphate and 6-phosphogluconate dehydrogenases following induction by diet or thyroid hormone. J. Biol. Chem. 257:11829-11835.

4. Oppenheimer, J. H., H. L. Schwartz, C. N. Mariash, W. B. Kinlaw, N. C. W. Wong, and H. C. Freake. 1987. Advances in our understanding of thyroid hormone action at the cellular level. Endocr. Rev. 8:288-308.

5. Jump, D. B., P. Narayan, H. C. Towle, and J. H. Oppenheimer. 1984. Rapid effects of thyroid hormone on hepatic gene expression. J. Biol. Chem. 259:2789-2797.

6. Narayan, P., C. W. Liaw, and H. C. Towle. 1984. Rapid induction of a specific nuclear mRNA precursor by thyroid hormone. Proc. Natl. Acad. Sci. USA. 81:4687-4691.

7. Strait, K. A., W. B. Kinlaw, C. N. Mariash, and J. H. Oppenheimer. 1989. Kinetics of induction by thyroid hormone of the two hepatic mRNAs coding for cytosolic malic enzyme in the hypothyroid and euthyroid states. J. Biol. Chem. 264:19784-19789.

8. Freake, H. C., H. L. Schwartz, and J. H. Oppenheimer. 1989. The regulation of lipogenesis by thyroid hormone and its contribution to thermogenesis. Endocrinology. 125:2868-2874.

9. Bilezikian, J. P., and J. N. Loeb. 1983. The influence of hyperthyroidism and hypothyroidism on $\alpha$ - and $\beta$-adrenergic receptor systems and adrenergic responsiveness. Endocr. Rev. 4:378-388.

10. Debons, A. F., and I. L. Schwartz. 1961. Dependence of the lipolytic action of epinephrine in vitro upon thyroid hormone. J. Lipid Res. 2:86.

11. Deykin, D., and M. Vaughn. 1963. Release of free fatty acids by adipose tissue from rats treated with triiodothyronine or propylthiouracil. J. Lipid Res. 4:200-203.

12. Fisher, J. N., and E. G. Ball. 1967. Studies on the metabolism of adipose tissue: the effect of thyroid status upon oxygen consumption and lipolysis. Biochem. 6:637-647.

13. Ros, M., J. K. Northrup, and C. C. Malbon. 1988. Steady state levels of G-protein and b-adrenergic receptors in rat fat cells. J. Biol. Chem. 263:43624368.

14. Rapiejko, P. J., D. C. Watkins, M. Ros, and C. C. Malbon. 1989. Thyroid hormones regulate G-protein $\beta$-subunit mRNA expression in vivo. J. Biol. Chem. 264:16183-16189.

15. Elks, M. L., and V. C. Manganiello. 1985. Effects of thyroid hormone on regulation of lipolysis and adenosine 3',5'-monophosphate metabolism in 3T3-L adipocytes. Endocrinology. 117:947-953.

16. Van Inwegen, R. G., G. A. Robison, W. J. Thompson, K. J. Armstrong, and K. E. Stouffer. 1975. Cyclic nucleotide phosphodiesterases and thyroid hormones. J. Biol. Chem. 250:2452-2456.

17. Engfeldt, P., P. Arner, P. Bolinder, A. Wennlund, and J. Ostman. 1982. Phosphodiesterase activity in human subcutaneous adipose tissue in hyper- and hypothyroidism. J. Clin. Endocrinol. Metab. 54:625-629.

18. Barker, S. B., and H. M. Klitgaard. 1952. Metabolism of tissues excised from thyroxine-treated rats. Am. J. Physiol. 170:81-86.

19. Tata, J. R., L. Ernster, O. Lindberg, E. Arrhenius, S. Pederson, and R. Hedman. 1963. The actions of thyroid hormones at the cell level. Biochem. 86:408-428.

20. Konstantinides, F. M., K. A. Boehm, W. J. Radmer, M. C. Storm, J. T. 
Adderly, S. A. Weisdorf, and F. B. Cerra. 1988. Pyrochemiluminescence: real time, cost effective method for determining total urinary nitrogen in clinical nitrogen balance studies. Clin. Chem. 34:2518-2520.

21. Stansbie, D., R. W. Brownsey, M. Crettaz, and R. M. Denton. 1976. Acute effects in vivo of anti-insulin serum on rates of fatty acid synthesis and activities of acetyl-coenzyme A carboxylase and pyruvate dehydrogenase in liver and epididymal adipose tissue of fed rats. Biochem. J. 160:413-416.

22. Bligh, E. G., and W. J. Dyer. 1959. A rapid method of total lipid extraction and purification. Can. J. Biochem. Physiol. 37:911-917.

23. Maniatis, T., E. F. Fritsch, and J. Sambrook. 1982. Molecular Cloning: A Laboratory Manual. Cold Spring Harbor Laboratories, Cold Spring Harbor, NY.

24. Mariash, C. N., S. Seelig, and J. H. Oppenheimer. 1982. A rapid, inexpensive quantitative technique for the analysis of two-dimensional electrophoretograms. Anal. Biochem. 121:388-394.

25. Forciea, M. A., H. L. Schwartz, H. C. Towle, C. N. Mariash, F. E. Kaiser, and J. H. Oppenheimer. 1981. Thyroid hormone-carbohydrate interaction in the rat. J. Clin. Invest. 67:1739-1747.

26. Flatt, J. P. 1978. The biochemistry of energy expenditure. In Recent Advances in Obesity Research. G. A. Bray, editor. Newman, London. 2:211-228.

27. Pilkis, S. J., and M. R. El-Maghrabi. 1988. Hormonal regulation of hepatic gluconeogenesis and glycolysis. Annu. Rev. Biochem. 57:755-783.

28. Smith, E. L., R. L. Hill, I. R. Lehman, R. J. Lefkowitz, P. Handler, and A. White. 1983. Principles of Biochemistry. 7th ed. McGraw-Hill Book Co., New York. 428-430.

29. Stralfors, P., H. Olsson, and P. Belfrage. 1987. Hormone Sensitive Lipase in the Enzymes. Vol. 18. P. Boyert, editor. Academic Press, New York. 147-177.

30. Christensen, N. J. 1973. Plasma noradrenaline and adrenaline in patients with thyrotoxicosis and myxedoema. Clin. Sci. Mol. Med. 45:163-171.

31. Coulombe, P., J. H. Dussault, and P. Walker. 1977. Catecholamine metab olism in thyroid disease: norepinephrine secretion rate in hyperthyroidism and hypothyroidism. J. Clin. Endocrinol. \& Metab. 1185-1189.

32. Wahrenberg, H., P. Engfeldt, P. Arner, A. Wennlund, and J. Ostman
1986. Adrenergic regulation of lipolysis in human adipocytes: findings in hyperand hypothyroidism. J. Clin. Endocrinol. \& Metab. 63:631-638.

33. Mayer, J. 1955. Regulation of energy intake and the body weight: the glucostatic theory and the lipostatic hypothesis. Ann. NY. Acad. Sci. 63:15-43.

34. Kennedy, G. C. 1952-53. The role of depot fat in the hypothalamic control of food intake in the rat. Proc. R. Soc. Lond. B. Biol. Sci. 140:578-592.

35. Edelman, I. S., and F. Ismail-Beigi. 1974. Thyroid thermogenesis and active sodium transport. Rec. Prog. Horm. Res. 30:235-257.

36. Sestoft, L. 1980. Metabolic aspects of the calorigenic effect of thyroid hormone in mammals. Clin. Endocrinol. 13:489-506.

37. Dillmann, W. H. 1984. Hormonal influences on cardiac myosin ATPase activity and myosin isoenzyme distribution. Mol. Cell. Endocrinol. 34:169-181.

38. Rohrer, D., and W. H. Dillmann. 1989. Thyroid hormone markedly increases the mRNA coding for sarcoplasmic reticulum $\mathrm{Ca}^{2+}$-ATPase in the rat heart. J. Biol. Chem. 263:6941-6944.

39. Pou, M. A., and J. Torresani. 1989. Coordinated stimulation by triiodothyronine of fatty acid synthesis and isoproteranol-sensitive fatty acid release in two preadipocyte cell lines of lean or genetically obese mice. Horm. Metab. Res. 21:468-472.

40. Weirich, R. T., H. L. Schwartz, and J. H. Oppenheimer. 1987. An analysis of the interrelationship of nuclear and plasma triiodothyronine in the sea lamprey, lake trout and rat: evolutionary considerations. Endocrinology. 120:664677.

41. Gorbman, A., and H. A. Bern. 1962. A Textbook of Comparative Endocrinology. John Wiley \& Sons, Inc., New York.

42. Parizkova, J., and Z. Koutecky. 1968. The effect of age and differen motor activity on fat, lipoprotein-lipase activity and relative weight of internal organs, heart and skeletal muscle. Physiol. Bohemoslov. 17:179-189.

43. Harris, P. M. 1980 . Changes in adipose tissue of the rat due to early undernutrition followed by rehabilitation: body composition and adipose tissue cellularity. Br. J. Nutr. 43:15-26.

44. Babineau, L. M., and E. Page. 1955 . On body fat and body water in rats. Can. J. Biochem. Physiol. 33:970-979. 